\title{
PENINGKATAN PENDAPATAN MASYARAKAT DESA PATTALASSANG MELALUI MANAJEMENISASI UMBI MENJADI KERIPIK SINGKONG
}

\author{
Gunawan $^{1}$, Herman Sjahruddin' ${ }^{2 *}$ Muh.Akil Zaury ${ }^{2}$, Putri Purnama ${ }^{2}$, Muh. Syukri ${ }^{2}$ \\ ${ }^{1}$ Program Studi Akuntansi, Sekolah Tinggi Ilmu Ekonomi Makassar Bongaya \\ ${ }^{2}$ Program Studi Manajemen, Sekolah Tinggi Ilmu Ekonomi Makassar Bongaya \\ email: herman.sjahruddin@stiem-bongaya.ac.id
}

\begin{abstract}
The wide area of the community's cassava garden in Pattalasang village, Pattalasang district, Gowa regency resulted in an abundance of community cassava yields, but on the other hand these results are not managed properly, the community only sells to traditional markets and collectors while demand for cassava is very limited, as a result a lot of cassava is damaged (rot). This condition is the reason for adding the economic value of the people's crops. Efforts are made for this purpose, namely by increasing the usefulness of cassava through the manufacture of chips to minimize cassava that is not absorbed by the market and collectors so as to increase the economic income of the community. This method of community service begins with observations and interviews then continues with socialization to explain to farmers that cassava can be processed into a high economic value product, demonstrations by involving the community (farmers) so that they can make crispy and savory cassava chips. The results of this community service in collaboration with SMEs as partners with this activity have an impact on the emergence of new knowledge and skills and their application in utilizing and developing cassava products by adding value and usefulness.
\end{abstract}

Keywords: cassava chips; pattallassang village; tubers

\begin{abstract}
Abstrak: Luasnya area kebun singkong masyarakat Desa Pattalasang Kecamatan Pattalasang Kabupaten Gowa mengakibatkan melimpahnya hasil panen singkong masyarakat, namun pada sisi lain hasil tersebut tidak dikelola dengan baik, masyarakat hanya menjual ke pasar tradisional dan pengumpul sementara permintaan terhadap singkong sangat terbatas, akibatnya banyak singkong yang rusak (membusuk). Kondisi ini menjadi alasan dilakukannya penambahan nilai ekonomis dari hasil panenan masyarakat. Upaya yang dilakukan untuk maksud tersebut, yaitu dengan cara menambah daya guna singkong melalui pembuatan keripik untuk meminimalisir singkong yang tidak terserap oleh pasar dan pengumpul sehingga dapat meningkatkan pendapatan ekonomi masyarakat. Metode yang dilakukan pada pengabdian masyarakat ini diawali dengan observasi dan wawancara kemudian dilanjutkan dengan sosialisasi untuk menjelaskan kepada petani bahwa singkong dapat diolah menjadi produk yang bernilai ekonomis tinggi, demonstrasi dengan melibatkan masyarakat agar mereka dapat membuat keripik singkong yang renyah dan gurih. Hasil pengabdian masyarakat ini berkolaborasi dengan UKM sebagai mitra yang dengan kegiatan ini berdampak pada munculnya pengetahuan dan ketarampilan baru serta mengaplikasikannya dalam memanfaatkan dan mengembangkan produk singkong dengan menambah nilai dan kegunaannya.
\end{abstract}

Kata kunci: keripik singkong; pattallassang; umbi 
Jurdimas (Jurnal Pengabdian Kepada Masyarakat) Royal

Vol. 5 No. 1, Januari 2022, hlm. 45 - 52

ISSN 2614-7912 (Print)

DOI: https://doi.org/10.33330/jurdimas.v5i1.1101

ISSN 2622-3813 (Online)

Available online at https:/jurnal.stmikroyal.ac.id/index.php/jurdimas

\section{PENDAHULUAN}

Kabupaten Gowa merupakan salah satu kabupaten yang berada di provinsi Sulawesi Selatan yang wilayah kerjanya terdiri dari 18 kecamatan, salah satu diantaranya adalah kecamatan Pattallassang. Peraturan Presiden Republik Indonesia Nomor 55 Tahun 2011 tentang rencana tata ruang kawasan perkotaan makassar, Maros, Sungguminasa, dan Takalar merupakan pusat pembangunan kawasan Metropolitan Maminasata adalah kecamatan Pattalassang. Secara administrative wilayah kecamatan Pattalassang memiliki luas terdiri dari \pm 1.038 ha., dengan populasi penduduk sebesar 23.601 jiwa dan terbagi pada delapan desa masing-masing disebutkan sebagai: Desa Panaikang, Pattallassang, Je'nemadinging, Paccelekang, Pallantikang, Borong Pa'lala, Sunggumanai dan Timbuseng (Brotowati et al., 2019) .

Desa Pattallassang merupakan salah satu penghasil singkong terbesar di Kabupaten Gowa, namun sayangnya singkong yang ada hanya ditanam secara tradisional oleh petani dan dijual secara langsung ke pasar dan kepada pengumpul dengan harga yang relatif murah hal ini dilakukan karena masyarakat memiliki keterbatasan pengetahuan dalam menambah nilai dan kegunaan dari singkong yang dihasilkan (Martati \& Kusrihandayani, 2020).

Kajian terhadap inovasi singkong menjadi keripik telah banyak dilakukan sebelumnya, seperti pada pengabdian kepada masyarakat yang dilakukan (Henakin \& Taena, 2018) melakukan pengelolaan singkong dengan menggunakan singkong, minyak goreng, gula pasir, garam meja, dan cabai merah untuk diolah menjadi keripik. Hasil dari pengabdian kepada masyarakat yang dilakukan secara bersama-sama dengan ke- lompok usaha tani yang ada menunjukkan jika keripik singkong yang dihasilkan dapat meningkatkan pendapatan anggota kelomnpok usaha tani sebesar \pm 3 juta rupian per bulan.

Pengabdian serupa juga dilakukan (Sophia et al. 2020) melalui metode sosialisasi dan pelatihan serta dengan demonstrasi produksi singkong frozen berkolaborasi dengan kelompok wanita tani (KWT), dengan melibatkan ibu PKK sebagai peserta pelatihan dan dan Ibu Rumah Tangga pada 3 Rukun Tangga di kelurahan Mentangor kecamatan Tenayan Raya. Hasil pelaksanaan kegiatan menunjukkan jika pelatihan dapat memberikan kontribusi positif bagi pengembangan pengetahuan dan wawasan serta pendapatan peserta pelatihan

Pernyataan tersebut juga terkonfirmasi pada studi yang dilakukan (Sulaiman \& Natawidjaja, 2019) yang mencoba menganalisis peluang perolehan margin pada 70 pengusaha IKM keripik singkong di Kota Cimahi, hasil wawancara dan analisis data membuktikan jika proses pengolahan keripik singkong walaupun masih menggunakan peralatan sederhana namun nilai tambah yang diperoleh UMKM berada pada rentang $15 \%-40 \%$, Sehingga pengelolaan keripik singkong dapat dapat dinyatakan berada pada kategori sedang dan memberikan keuntungan.

Bersandar pada ketiga studi tersebut, maka dapat dinyatakan jika pengelolaan singkong menjadi keripik merupakan usaha yang menjanjikan dalan upaya peningkatan pendapatan masyarakat. Berdasarkan fakta tersebut maka menjadi alasan dilakukannya pengabdian pada masyarakat bekerjasama dengan Badan Usaha Milik Desa (BUMDes) sebagai mitra pengabdian. 
Jurdimas (Jurnal Pengabdian Kepada Masyarakat) Royal

Vol. 5 No. 1, Januari 2022, hlm. 45 - 52

ISSN 2614-7912 (Print)

DOI: https://doi.org/10.33330/jurdimas.v5i1.1101

ISSN 2622-3813 (Online)

Available online at https:/jurnal.stmikroyal.ac.id/index.php/jurdimas

\section{METODE}

Pelaksanaan pengabdian pada masyarakat ini dilaksanakan selama \pm 90 hari melalui beberapa metode; pada tahap awal dilakukan observasi yang dilaksanakan dengan meninjau secara langsung perkebunan singkong milik masyarakat untuk mengetahui kadar air dan kualitas singkong. sosialisasi dan praktik secara langsung yang dilakukan dengan bekerja sama dengan Badan Usaha Milik Desa (BUMDes) untuk menjadi contoh agar dapat dilaksanakan oleh ibu-ibu PKK Desa Pattallassang.

Pentahapan berikutnya dilakukan dengan cara melakukan pembelajaran dan praktik tentang pegolahan singkong menjadi keripik dan potensi peman-faatanya dengan untuk dijadikan olahan pangan untuk meningkatkan pendapatan masyarakat dalam pemenuhan kebutuhan dapur ibu-ibu PKK desa Pattallassang.

Setelah dilakukan observasi selama kurang lebih seminggu di desa Pattalasang selanjutnya kami mengadakan penyuluhan selama 2 hari kepada masyarakat tentang pengolahan produk hasil pertanian singkong yang bertujuan untuk memberikan pengetahuan kepada masyarakat bahwa singkong hasil panen yang diperoleh tidak hanya dimanfaatkan sebagai bahan makanan yang dimasak seadanya kemudian dipasarkan, akan tetapi dapat dilakukan pengolahan lebih lanjut ke berbagai jenis produk salah satunya adalah dengan membuat produk makanan keripik singkong yang tentunya akan lebih bernilai ekonomis.

Penciptaan nilai tambah dilakukan melalui perubahan wujud singkong menjadi keripik yang prosesnya dilakukan berulang-ulang untuk menghasilkan produk yang memiliki cita rasa gurih dan renyah. Penciptaan singkong dengan rasa gurih dan renyah dilakukan melalui be- berapa tahapan, diantaranya tahapan uji coba, penciptaan produk awal dan pada akhirnya membuat produk jadi (siap jual) dengan menggunakan merk keripik Pattallassang.

Hal ini dimaksudkan untuk mengangkat nama desa Pattallassang untuk dapat dikenal oleh masyarakat luas. Alasan lain mengapa singkong yang dipilih untuk diolah menjadi keripik karena selain desa pattallassang menghasilkan singkong yang melimpah juga dari sisi kesehatan, singkong dapat menurunkan kadar rematik pada diri manusia (Utama \& Rukismono, 2018).

Penciptaan nilai tambah singkong menjadi kripik merupakan penambahan nilai suatu produk sebelum dilakukan proses produksi dengan setelah dilakukan proses produksi. Pengolahan Umbi menjadi keripik singkong adalah untuk meningkatkan keawetan Umbi sehingga layak untuk dikonsumsi dan memanfaatkan Umbi agar memperoleh nilai jual yang tinggi dipasaran. Dengan adanya kegiatan usaha pengolahan Umbi menjadi keripik singkong yang mengubah bentuk dari produk primer menjadi produk baru yang lebih tinggi nilai ekonomisnya setelah melalui proses produksi, maka akan dapat memberikan nilai tambah karena dikeluarkan biayabiaya sehingga terbentuk harga baru yang lebih tinggi dan keuntungan yang lebih besar bila dibandingkan tanpa melalui proses produksi. Untuk mengetahui besar nilai tambah yang diberikan keripik singkong pada Umbi sebagai bahan baku maka diperlukan analisis nilai tambah sehingga bisa diketahui apakah usaha yang dijalankan tersebut efisien dan memberikan keuntungan (Intyas, 2020). 
Available online at https:/jurnal.stmikroyal.ac.id/index.php/jurdimas

\section{PEMBAHASAN}

Hasil penyuluhan dilapangan bahwa masyarakat di desa Pattallassang hanya mampu mengelola hasil panen singkong dengan menjual langsung kepada pengepul dengan nilai yang sangat rendah. Maka dari itu kami memberikan penyuluhan kepada para petani di desa pattallassang tentang bagaimana memanfaatkan umbi menjadi keripik singkong yang bisa menambah harga jual dan nilai tambah kepada ibu-ibu rumah tangga dan ibu PKK di desa Pattallassang sehingga para petani dapat meningkatkan pengolahan umbi untuk menghasilkan suatu produk yang relative awet dengan tujuan untuk menambah jenis produk yang dihasilkan.

Penyuluhan dan pelatihan Keripik Singkong mampu memberikan keterampilan kepada para petani untuk dapat mengolah hasil panennya menjadi lebih bernilai dan dapat meningkatkan nilai ekonomi dikawasan desa Pattallassang kecamatan Pattallassang kabupaten Gowa dengan memberikan wawasan bahwa dengan mengelola singkong dapat menambah pendapatan bagi ibu-ibu PKK di desa Pattallassang.

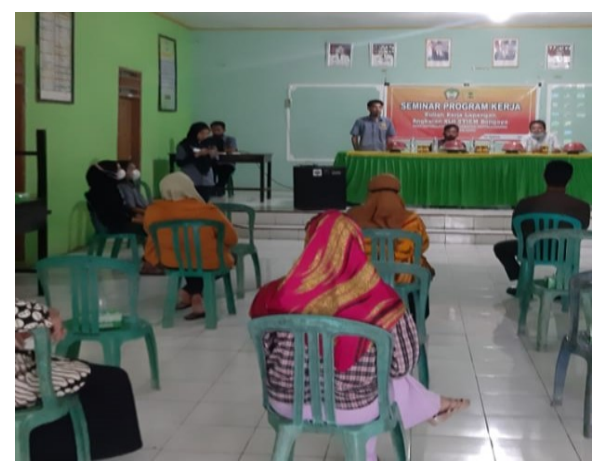

Gambar.1 Penyuluhan dan Motivasi Untuk Ibu-Ibu Pkk

Kegiatan selanjutnya, menentukan produk makanan yang dapat diolah dari hasil pertanian Singkong di desa Pattalasang. Penentuan jenis olahan makanan yang cocok dengan hasil pertanian Singkong, agar pengolahan yang dilakukan dapat maksimal dan tidak menyulitkan masyarakat untuk memperoleh bahan baku produk makanan. Mayoritas tanaman singkong di desa Pattallassang merupakan jenis singkong yang sangat baik untuk diolah menjadi Keripik Singkong.

Tabel.1 Bahan Baku (rincian biaya)

\begin{tabular}{llllll}
\hline \multicolumn{1}{c}{ Item } & $\begin{array}{c}\text { Harga } \\
\text { satuan/kg }\end{array}$ & $\begin{array}{c}\text { Jumlah } \\
\text { bahan }\end{array}$ & Total & Ket & $\begin{array}{c}\text { Biaya pem- } \\
\text { buatan }\end{array}$ \\
\hline Umbi & Rp.7.500 & $2 \mathrm{~kg}$ & $\mathrm{Rp} .15 .000$ & $\begin{array}{l}1 \text { kali } \\
\text { pemakaian }\end{array}$ & Rp. 15.000 \\
\hline $\begin{array}{l}\text { Bumbu tabur } \\
\text { balado }\end{array}$ & $\mathrm{Rp} .5000$ & $2 \mathrm{pcs}$ & $\mathrm{Rp} .10 .000$ & $\begin{array}{l}1 \text { kali } \\
\text { pemakaian }\end{array}$ & Rp. 10.000 \\
\hline $\begin{array}{l}\text { Bumbu tabur } \\
\text { jagung bakar }\end{array}$ & $\mathrm{Rp} .5000$ & $2 \mathrm{pcs}$ & $\mathrm{Rp} .10 .000$ & $\begin{array}{l}1 \text { kali } \\
\text { pemakaian }\end{array}$ & Rp. 10.000 \\
\hline Minyak goreng & $\mathrm{Rp} .28 .000$ & 2 liter & $\mathrm{Rp} .28 .000$ & $\begin{array}{l}1 \text { kali } \\
\text { pemakaian }\end{array}$ & Rp. 28.000 \\
\hline Standing pouch & $\mathrm{Rp} .2 .700$ & $35 \mathrm{pcs}$ & $\mathrm{Rp} .94 .500$ & $\begin{array}{l}1 \text { kali } \\
\text { pemakaian }\end{array}$ & Rp. 94.500 \\
\hline Jumlah & $\mathrm{Rp} .48 .200$ & - & $\mathrm{Rp} .157 .500$ & - & Rp. 157.500 \\
\hline
\end{tabular}


Pembuatan keripik singkong tergolong relative mudah dengan pemanfaatan peralatan dan perlengkapan dapur yang dimiliki masyarakat desa. Modal awal yang perlu disiapkan pun relative murah yaitu dengan menyiapkan Umbi 2 kilogram dengan total harga Rp.15.000,-. Penyedap rasa dengan berbagai Varian rasa yaitu Balado dan Jagung Bakar dengan total harga Rp.5000,-/bungkus. Untuk singkong yang akan digunakan pun harus singkong yang baru di panen langsung dari lahan pertanian masyarakat agar tidak mengalami penurunan kualitas (rusak).

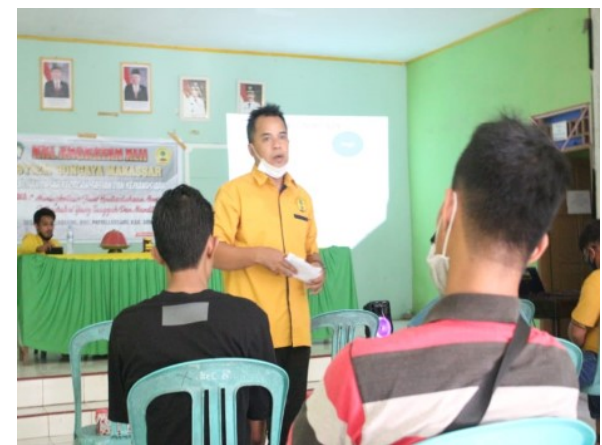

Gambar. 2 Sosialisasi dan Penyuluhan Keripik Singkong

Proses pengemasan menggunakan Standing Pouch Ukuran sedang dengan harga Rp.2.700,-/bungkus. Untuk menghasilkan 35 bungkus keripik singkong hanya membutuhkan modal Rp. 157.500,- dan dapat dijual dengan harga Rp. 10.000,-/bungkus. Sehingga dalam 2 $\mathrm{kg}$ singkong dapat menghasilkan 35 bungkus keripik singkong dan masyarakat dapat memperolah penghasilan sebesar Rp.350.000,- peningkatan yang dihasilkan oleh masyarakat desa Pattallassang dalam satu kali proses produksi yang digunakan dalam $2 \mathrm{~kg}$ singkong saja bisa menjadi 10 kali lipat dibandingkan jika singkong langsung dipasarkan.

Keseluruhan biaya yang digunakan dalam membuat keripik sebanyak 35 pcs, untuk biaya pembuatan dibutuhkan anggaran sebesar Rp.157.500,-. Berdasarkan kondisi tersebut maka dapat diporeloh penjualan sebesar 35 pcs x Rp.48.200, sehingga pendapatan kotor yang dihasilkan Rp.1.687.000,-.

Adapun cara yang digunakan untuk membuat/menghasilkan keripik singkong yang gurih dan renyah, di tunjukkan sebagai berikut:

\section{Cara Pembuatan}

1. Kupas singkong lalu bersihkan dengan air bersih

2. Kemudian singkong diiris tipis menggunakan pisau iris atau alat khusus

3. Irisan singkong di masukkan ke dalam wadah yang berisi campuran air bersih yang telah diberi garam. Rendam selama 15 menit. Lalu tiriskan

4. Panaskan wajan lalu masukkan minyak goreng. Kemudian irisan singkong digoreng hinggga berwarna kuning kecoklatan.

5. Bumbu tabur yang telah disiapkan

6. Masukan irisan singkong yang telah ditiriskan ke dalam adonan bumbu yang telah disiapkan dan aduk secara merata

7. Siap dinikmat.

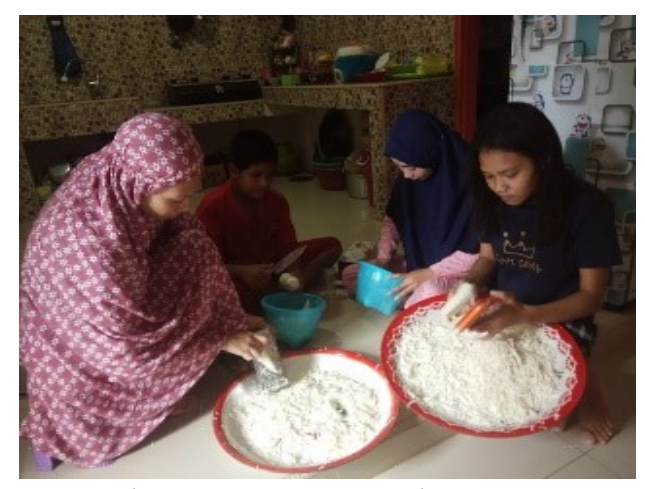

Gambar.3 Proses Pembuatan Dan Penggorengan 


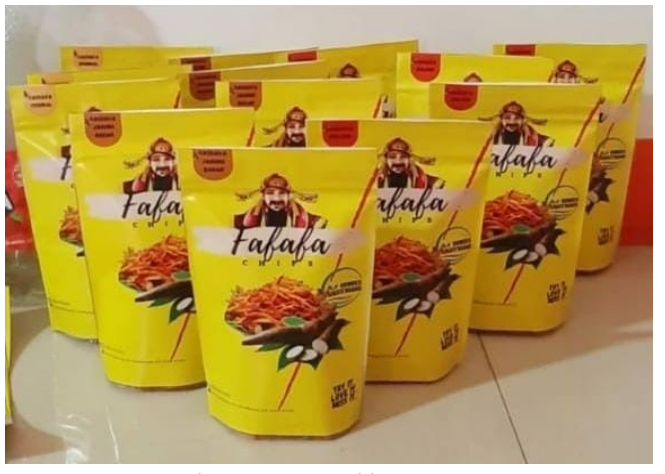

Gambar.4 Hasil Pengemasan

Pada umumnya konsumen pertama kali tertarik untuk membeli produk makanan dan minuman kemasan karena brand atau daya tarik dari kemasannya (Willya \& Nurjanah, 2019; Sjahruddin et al., 2020). Dalam hal ini, atribut kemasan berfungsi sebagai media komunikasi dan menumbuhkan branding, sehingga sering disebut sebagai silent salesman (Hanifawati et al., 2017). Kemasan mempengaruhi keputusan pembelian konsumen (Lukman, 2014).

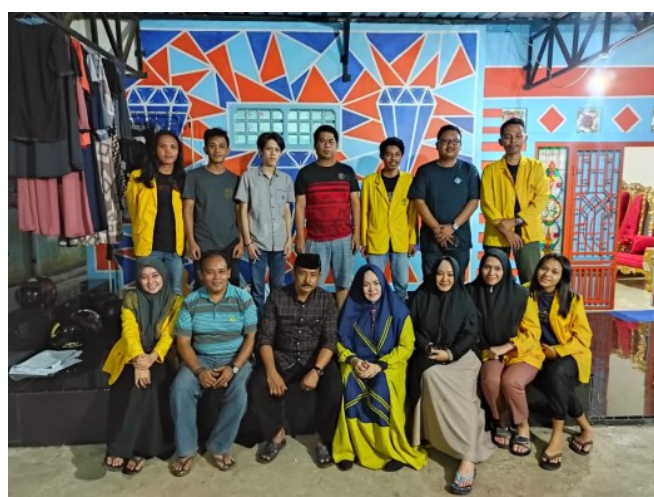

Gambar. 5 Foto Bersama Peserta

Luaran dari kegiatan ini, masyarakat diharapkan mampu menghasilkan produk Keripik Singkong yang dikemas dan diberi merek sehingga sudah mulai dipasarkan. Selain itu pemanfaatan teknologi untuk pemasaran online agar penjualan Kripik Singkong lebih mudah dan dijangkau oleh masyarakat banyak. Sehingga penjualan Keripik Singkong dapat menambah pendapatan masyarakat untuk memenuhi kebutuhan sehari-hari masyarakat utamanya ibu-ibu yang terafiliasi dengan PKK Desa Pattallassang.

\section{SIMPULAN}

Kegiatan penyuluhan Keripik Singkong mampu memberikan keterampilan kepada para petani dan masyarakat termotivasi dan sangat antusias dalam mengolah singkong menjadi keripik karena akan diperolah keuntungan yang lebih besar daripada menjual singkong langsung tanpa pengolahan dan pada proses pengolahannya pun tidak terlalu sulit untuk dikerjakan sehingga dalam mengolah hasil panennya menjadi lebih bernilai dan dapat meningkatkan nilai tambah ekonomi dikawasan desa Pattallassang kecamatan Pattallassang kabupaten Gowa.

\section{UCAPAN TERIMA KASIH}

Ucapan terimakasih kepada Pemerintahan desa Pattallassang Kecamatan Pattallassang Kabupaten Gowa (Camat beserta jajaranya) dan Badan Usaha Milik Desa (BUMDES) yang telah bekerja sama dalam pengembangan produk keripik singkong, serta masyarakat yang terlibat langsung dalam pengolahan singkong menjadi keripik ubi selama \pm 90 hari di desa Pattallassang. 


\section{DAFTAR PUSTAKA}

Brotowati, S., Sofia, I., \& Yustiono, H. S. (2019). IbM Pembinaan Remaja Di Dusun Bu'rung Bu'rung Desa Pattalassang, Kecamatan Pattalassang, Kabupaten Gowa. In Seminar Nasional Hasil Penelitian \& Pengabdian Kepada Masyarakat (SNP2M) 414-419.

Emilda, E., Wulandari, T., \& Lazuarni, S. (2021). Pelatihan Keterampilan Menjahit Masker Kain Dalam Memanfaatkan Peluang Bisnis Era Pandemi Covid-19. Jurdimas (Jurnal Pengabdian Kepada Masyarakat) Royal, 4(2), 111120.

Hanifawati, T., Suryantini, A., \& Mulyo, J. H. (2017). Pengaruh Atribut Kemasan Makanan Dan Karakteristik Konsumen Terhadap Pembelian. Agriekonomika, 6(1). https://doi.org/10.21107/agriekon omika.v6il.1895

Henakin, F. K., \& Taena, W. (2018). Analisis Nilai Tambah Singkong Sebagai Bahan Baku Produk Keripik di Kelompok Usaha Bersama Sehati Desa Batnes Kecamatan Musi. Agrimor, 3(2), 23-26.

Herlina, M., Syahfitri, J., Lubis, R., Sulaiman, E., \& Nopriyeni, N. (2021). Pelatihan Pembuatan Keripik Daun Kopi Di Desa Cugung Lalang Kecamatan Kepahiang Kabupaten Kepahiang. Jurdimas (Jurnal Pengabdian Kepada Masyarakat) Royal, 4(2), 141-146.

Intyas, C. A. (2020). Analisis Nilai Tambah Usaha Kerupuk Ikan Cumi Di Desa Weru, Kecamatan Paciran, Kabupaten Lamongan.
JFMR-Journal of Fisheries and Marine Research, 4(2), 214-221. https://doi.org/10.21776/ub.jfmr.2 020.004.02.5

Lukman, M. D. (2014). Analisis Pengaruh Ekuitas Merek Terhadap Keputusan Pembelian Dan Kepuasan Konsumen Produk Teh Botol Sosro Kemasan Kotak. Jurnal Administrasi Bisnis, 10(1), 64-81.

https://doi.org/10.26593/jab.v10i1 .1222 .

Martati, I., \& Kusrihandayani, D. (2020). Prosiding 4. Identifikasi Potensi Kemandirian UMKM Di Kota Samarinda Melalui Pelatihan Manajemen Usaha, 124-129.

Republik Indonesia (2011). Peraturan Presiden (PERPRES) Nomor 55 Tentang Rencana Tata Ruang Kawasan Perkotaan Makassar, Maros, Sungguminasa, dan Takalar. Sekertariat Negara

Sjahruddin, H., Subar, M., Aiman, I., \& Aswar, A. (2020). Pemanfaatan Lahan Pekarangan Rumah dengan Menanam Sayur Mayur untuk Meningkatkan Ekonomi Masyarakat Desa Kelenna Bontongape Kecamatan Galesong Kabupaten Takalar. Cendekia: Jurnal Pengabdian Masyarakat, 2(2), 137-145.

Sophia, H., Dahliaty, A., Nugroho, T. T., \& Helianty, S. (2020). Inovasi produk olahan Singkong menjadi Singkong Frozen untuk meningkatkan pendapatan masyarakat. In Unri Conference Series: Community Engagement. Vol. 2, 488-493.

Sulaiman, S., \& Natawidjaja, R. S. (2019). Analisis Nilai Tambah Agroindustri Keripik Singkong (Studi Kasus Sentra Produksi 
Jurdimas (Jurnal Pengabdian Kepada Masyarakat) Royal

Vol. 5 No. 1, Januari 2022, hlm. 45 - 52

Available online at https://jurnal.stmikroyal.ac.id/index.php/jurdimas

Keripik Singkong Pedas di Kelurahan Setiamanah, Kecamatan Cimahi Tengah, Kota Cimahi). Jurnal Ilmiah Mahasiswa Agroinfo Galuh, 5(1), 973-986.

Utama, Y. A. K., \& Rukismono, M. (2018). Singkong-Man vs Gadung-Man. Papua. Aseni

Willya, \& Nurjanah, S. (2019). Pengaruh Perceived Quality Dan Brand Image Terhadap Brand Trust Produk Kosmetik Wardah Universitas Muhammadiyah
Ponorogo. Jurnal Ilmu

Manajemen Http://Jurnal.Um-

Palembang.Ac.Id/Ilmu_manajeme

n, $\quad 8(2), \quad 19$.

https://doi.org/10.32502/jimn

Wulandari, T., Emilda, E., \& Lazuarni, S. (2021). Pelatihan Kerajinan

Tangan Dalam Upaya Memanfaatkan Peluang Bisnis Di Era Pandemi. Jurdimas (Jurnal Pengabdian Kepada Masyarakat) Royal, 4(3), 281-286. 